\section{SDC truly international}

SIR - As spokesman of the Solenoidal Detector Collaboration (SDC), I am responding to the news item (Nature 362, $385 ; 1993$ ) about non-US funding for the SDC detector project. The SDC is an international collaboration involving more than 900 physicists and engineers, many of them from overseas, that has been working intensively over the past three years on the development of a detector intended to exploit the physics opportunities opened up by the Superconducting Super Collider (SSC), now under construction near Dallas.

There are several errors in your article: Professor "Ott" from Canada is really Professor Robert Orr, the National Science and Engineering Research Council is really the Natural Sciences etcetera, and the statement attributed to the French science attaché that "French scientists now working on the SDC are being paid by the SSC" is incorrect.

But I object most strongly to the negative tone of the article, well reflected in its title, "SSC detector collaborators shun financial commitments". It is correct that the non-US funding for the SDC detector, expected to be about 40 per cent of the total, is not yet firm. However, this is not surprising. Before specific requests can be made to funding agencies, the detector design and research and development must be sufficiently far advanced that one can define with some precision the in-kind contributions to be made by the non-US collaborating groups. The SDC is just reaching that stage, after successfully completing two intensive reviews, including one by a distinguished international group of scientists. The specific dollar numbers quoted in your article represent the value of the items that our non-US collaborators are hoping to provide, estimated according to US accounting rules. The SDC is developing specific countryby-country proposals which will, at the appropriate time, be submitted to the relevant funding agencies.

The tradition of international collaboration in the construction and exploitation of detectors in high-energy physics, with involvement much broader than just the country or countries financing the accelerator operation, is well established. There are unique facilities in Europe (LEP, HERA) and in Japan (TRISTAN), and American groups have been actively involved in experiments at these facilities with financial support from the US government, and in collaboration with groups from Europe, Japan, Canada and elsewhere. Similarly, some US facilities such as the Tevatron Collider at Fermilab provide unique capabilities, and groups from outside the United States are collaborating with US groups on experiments there.
The 40-TeV collision energy of the SSC will unquestionably open up unique scientific opportunities not available anywhere else in the foreseeable future. Participation in the SSC experimental programme by interested groups from outside the United States is therefore the natural continuation of a well-established and highly successful tradition.

\section{George H. Trilling}

Lawrence Berkeley Laboratory,

University of California,

Berkeley, California 94720, USA

Professor Trilling is correct in saying that French scientists working on the project were not paid salaries by SDC; we were misinformed by the French Embassy in Washington. - Editor, Nature.

\section{Overbiodiverse?}

SIR - While recently carrying out a literature search on the BIDS (Science Citation Index) database I was struck by the incidence of papers whose titles contained the word 'biodiversity' (see figure). Since the first record in 1987, and estimating the current year's total from the first three months, it is apparent that the rate of increase of biodiversity publications (by this criterion) is almost exactly exponen-

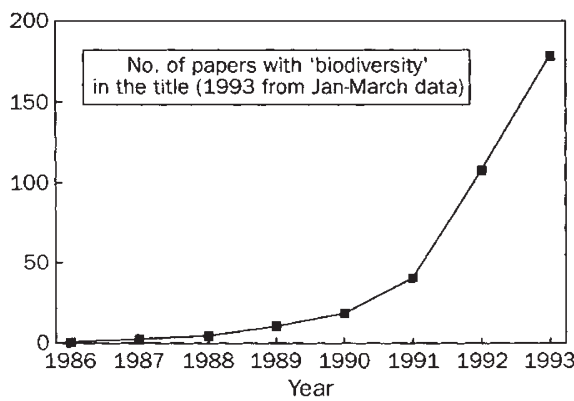

tial, with a doubling time very close to one year.

Does this trend indicate a growing awareness of the problem of defining and conserving biodiversity, or a tendency for the discussion of problems to substitute for the ability to solve them?

\section{Peter J. Hogarth}

Tropical Marine Research Unit and

Department of Biology,

University of York,

York YO1 5DD, UK

\section{Epidemic misuse}

SIR - We are distressed at the tendency to use terms referring to human diseases to describe those of nonhuman animals. Thus we have "epidemic" (for 'epizootic') ${ }^{1-6}$, "epidemiology" 'epizootology') $)^{6,7}$, "symptom" (for "sign') ${ }^{4-9}$ and "autopsy" (for 'necropsy') ${ }^{10}$

The derivation of the terms makes it plain that these are misusages. The particle-dem-derives from the Greek demos, meaning 'people' (whence also 'democracy'). A 'symptom' requires communication with a human patient, but a 'sign' of disease is evident by observation. Although the derivation of 'autopsy' does not restrict its use to people, the standard definition ${ }^{11}$ does.

The mixing of these terms in the same publication succinctly illustrates the confusion. Why are mass mortalities of sea urchins $^{2}$ in California and Canada "epizootics", but those in the Caribbean an "epidemic" 2 ? Is there ${ }^{6}$ an 'epidemiology' of fish epizootics? Signs of 'ecosystem distress' there may be ${ }^{6}$, but can there be 'signs and symptoms' thereof? What ${ }^{12}$ is the 'epidemiology' of 'epizootic apthae'?

We do not suppose that these mistaken substitutions are deliberate. They may be consequences of ignorance. Or are they manifestations of political correctness modulated by the view that there is no proper distinction between human and nonhuman animals?

Ernest H. Williams Jr, Lucy Bunkley-

Williams (Marine Ecological Disturbance Information Center, Department of Marine Sciences, University of Puerto Rico, POBox 908, Lajas, Puerto Rico 00667-0980, USA); John M. Grizzle (Department of Fisheries and Allied Aquaculture, Auburn University, Alabama 36489, USA); Esther C. Peters (Tetra Tech Inc. 10306 Eaton Place, Suite 340, Fairfax, Virginia 22030, USA); Donald V. Lightner (Department of Veterinary Science, University of Arizona, Tucson, Arizona 85721, USA); John Harshbarger (Registry of Tumors of Lower Animals, NHB-163, Smithsonian Institution, Washington, DC 20560, USA);

Aaron Rosenfield Northeast Fisheries Center, Oxford Laboratory, Railroad Avenue, Oxford, Maryland 21654, USA);

Renate Reimschuessel (Department of Pathology, Medical School Teaching Facility, University of Maryland School of Medicine, 10 South Pine Street, Baltimore, Maryland 21201, USA)

1. Gould, S. J. Nat. Hist. 6/91, 22 (1991)

2. Lessios, H. A. et al. Science 226, 335 (1984)

3. Rowan, R. \& Powers, D. A. Science 251, 1348-1351 (1991)

4. Lessios, H. A et al Coral Reefs 3 173(1984)

5. Lessios, H. A. A. Rev. Ecol. Syst. 19, 371 (1988)

6. Cairns, V. W. et al. (eds) Contaminant Effects on Fisheries (Wiley, New York, 1984)

7. Peters, E. C. Heligol. Wiss. Meeresunters 37, 113-137 (1984).

8. Grigg, R. W. Coral Reefs 11, 183-186 (1992)

9. Muehistein L. K Can J Bot 70, 2081-2088 (1992).

10. Novotny J. F. \& Beeman, J W. Progr. Fish.Cult $\mathbf{5 2}$ 162-170 (1990)

11. Post, G. \& Klontz, W. G. (eds), Glossary of Fish Health Terms (Amer. Fish. Soc. Fish. Health Section, 1977).

12. Siegmund, O. H. et al., The Merck Manual (Merck\& Co. Inc., Rahway, New Jersey, 1979)

13. Anderson, C. Nature 351, 89 (1991)

14. Nature 345, 648(1991)

14. Nature 345, 648 (1991).

16. Weissmann, C. Nature 349, 569-571 (1991), 